\title{
Complutum
}

ISSN: 1131-6993

\section{Una vasija decorada ibérica de función ceremonial: un espacio singular en el Coll del Moro (Gandesa, Tarragona)*}

\author{
Núria Rafel Fontanals ${ }^{1}$; Rafel Jornet Niella²; Pilar Burillo-Cuadrado ${ }^{3}$
}

Recibido: 28 de febrero de 2018 / Aceptado: 12 de noviembre de 2018.

Resumen. Se presenta un vaso ibérico del siglo III ane excepcionalmente decorado procedente del ámbito 8 del poblado del Coll del Moro de Gandesa (Tarragona). Se trata de una marmita cerámica de cierre hermético, elaborada a mano, de perfil globular, con dos asas horizontales torsionadas y profusa decoración geométrica y zoomorfa. Presenta un asa de pomo, maciza, subcuadrangular, que está decorada en cada uno de sus cuatro ángulos superiores con motivos plásticos, sendas cabezas de carnero estilizadas. El fondo interno de la vasija está decorado con una cruz esvástica en altorrelieve. Tanto el carnero como la cruz, los dos elementos decorativos más sobresalientes de la pieza, tienen un arraigado simbolismo relacionado con el culto al hogar y a los antepasados. La función de la vasija es, sin lugar a dudas, ritual. Entronca con cultos al hogar y a los antepasados ya atestiguados en la protohistoria de la Península Ibérica y pone de manifiesto que en el ámbito en el que se hallaba se desarrollaban ceremonias de culto. Dicho ámbito se ubica en lo que podemos llamar un barrio productivo o industrial del asentamiento donde se ha exhumado un conjunto arquitectónico dedicado al enriado del lino y a otras actividades textiles y otro dedicado a lagar y almacenaje de vino. El hallazgo aporta nuevas perspectivas sobre las actividades ceremoniales y el mobiliario de culto en el nordeste peninsular, tan avaro respecto a este tipo de información.

Palabras clave: Vaso litúrgico; nordeste de la Península ibérica; Cultura Ibérica; carnero; esvástica; ceremonias de culto

\section{An iberian decorated vessel of ceremonial function: a singular space in the Coll del Moro (Gandesa, Tarragona)}

\begin{abstract}
An exceptional decorated Iberian ceramic vase dating from the third century BC and coming from room 8 of the site of Coll del Moro de Gandesa (Tarragona) is presented. It is a hermetically sealed ceramic vessel, hand-made, with a globular profile, with two twisted horizontal handles and profuse geometric and zoomorphic decoration. It has a knob handle, solid, quadrangular, which is decorated in each of its four upper angles with plastic motifs, stylized ram heads. The inner bottom of the vessel is decorated with a swastika in high relief. Both the ram and the cross, the two most outstanding decorative elements of the piece, have an ingrained symbolism related to the cult of the home and the ancestors. The function of the vessel is, without a doubt, liturgical. It connects with cults to the home and to the ancestors already attested in the Protohistory of the Iberian Peninsula and shows that ceremonies of worship were taking place in the room in which it was discovered. This room is located in what can be called a productive or industrial neighborhood of the settlement of Coll del Moro where an architectural complex dedicated to textile workshop where flax was processed has been exhumed and another complex was dedicated to winery and wine storage. The finding brings new perspectives on the ceremonial activities and the liturgical items in the northeastern peninsular, so greedy regarding this type of information.
\end{abstract}

Key words: Liturgical vessel; northeast of the Iberian Peninsula; Iberian Culture; ram; swastika; cult ceremonies

Sumario: 1. Rasgos morfológicos y decorativos de la pieza. 2. El contexto arqueológico. 3. Acerca de la decoración de la pieza. 3.1. El carnero. 3.2. La esvástica. 4. Consideraciones finales: actividades domésticas y artesanales versus prácticas rituales. Bibliografía.

Cómo citar: Rafel Fontanals, N.; Jornet Niella, F.; Burillo-Cuadrado, P. (2018): Una vasija decorada ibérica de función ceremonial: un espacio singular en el Coll del Moro (Gandesa, Tarragona). Complutum, 29(1): 135-150. 
Durante la campaña de excavación que se llevó a cabo en $1993^{1}$ en el poblado del Coll del Moro de Gandesa se exhumó una pieza cerámica completa, de rasgos excepcionales. Recientemente, con motivo de su depósito en la sede de Barcelona del Museu d'Arqueologia de Catalunya para su incorporación a la exposición permanente, se finalizó su restauración ${ }^{2}$ En el presente artículo presentamos la vasija y su contexto.

\section{Rasgos morfológicos y decorativos de la pieza}

El vaso se recuperó aplastado, pero entero, cerca del ángulo este del ámbito 8 de poblado. Se trata de una marmita cerámica $(\mathrm{H}=43,2 \mathrm{~cm}$.) de cierre hermético, elaborada a mano, de perfil globular, con dos asas horizontales torsionadas y profusa decoración geométrica y zoomorfa (Figs. 1 y 2). El vaso está integrado por dos cuerpos, la marmita propiamente dicha y su correspondiente tapadera. La primera presenta fondo plano, borde entrante y labio biselado (D. boca $=$ 39,6 cm.; D. pie= 16 cm.; H. 25,2 cm.). Bajo el borde sobresale un baquetón subcuadrangular decorado con una línea poligonal incisa que forma una cenefa de triángulos y, bajo él y pegadas al mismo, las dos asas horizontales, trenzadas helicoidalmente y acabadas en cada uno de sus extremos a manera de volutas, quizás una estilización de unos cuernos de carnero. El fondo interno de la pieza (D. 13,2 cm.) presenta una decoración en relieve consistente en una cruz gamada o esvástica dextrógira y rectilínea que se destaca del fondo plano con una altura de 16 $\mathrm{mm}$. La tapadera $(\mathrm{H} .=18 \mathrm{~cm})$, de labio también biselado, encaja con el cuerpo inferior. Presenta un asa de pomo, maciza, subcuadrangular, que está decorada en cada uno de sus cuatro ángulos superiores con motivos plásticos, sendas cabezas de carnero estilizadas. La parte superior del pomo presenta una cruz aspada, incisa, limitada por puntos en sus extremos y con trazos transversales sobre ambas barras; sus laterales presentan motivos en flecha, también incisos, que continúan en el cuerpo de la tapadera. Esta última presenta un motivo plástico a manera de apéndice u orejeta consistente en la parte superior de la cabeza de un carnero que encaja con la barba del mismo, situado sobre el borde de la marmita, de modo que al tapar la marmita la cabeza del animal quedaba completa. La parte inferior de la cabeza, ubicada en el borde de la marmita, presenta dos perforaciones en la parte inferior que no llegan a traspasar el apéndice. La superficie de la tapadera presenta también decoración incisa consistente en cuatro motivos a manera de flecha doble que parten de cada uno de los lados del pomo y bajan hasta el cuerpo. Entre estos cuatro motivos se sitúan cuatro más en forma de líneas o tallos rematados con volutas afrontadas dos a dos. Una quinta flecha, más pequeña, se sitúa emergiendo de la testuz del carnero.

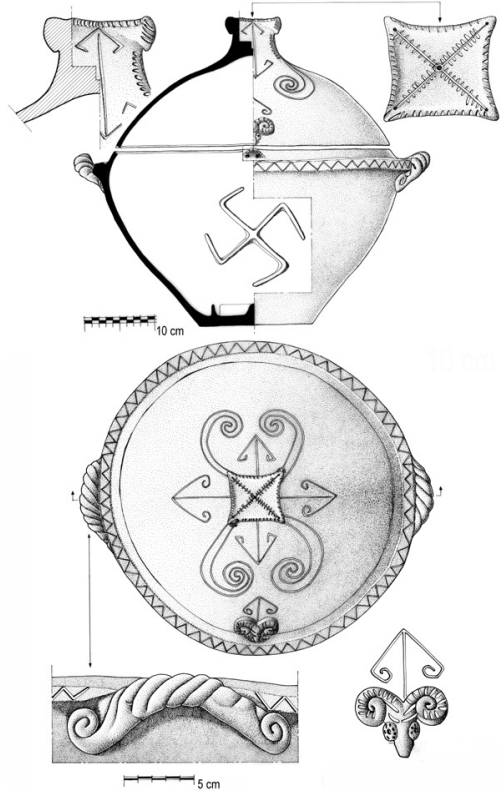

Figura 1. Marmita cerámica recuperada en el Ámbito 8 del poblat del Coll del Moro de Gandesa (dibujo Antoni Llussà) 


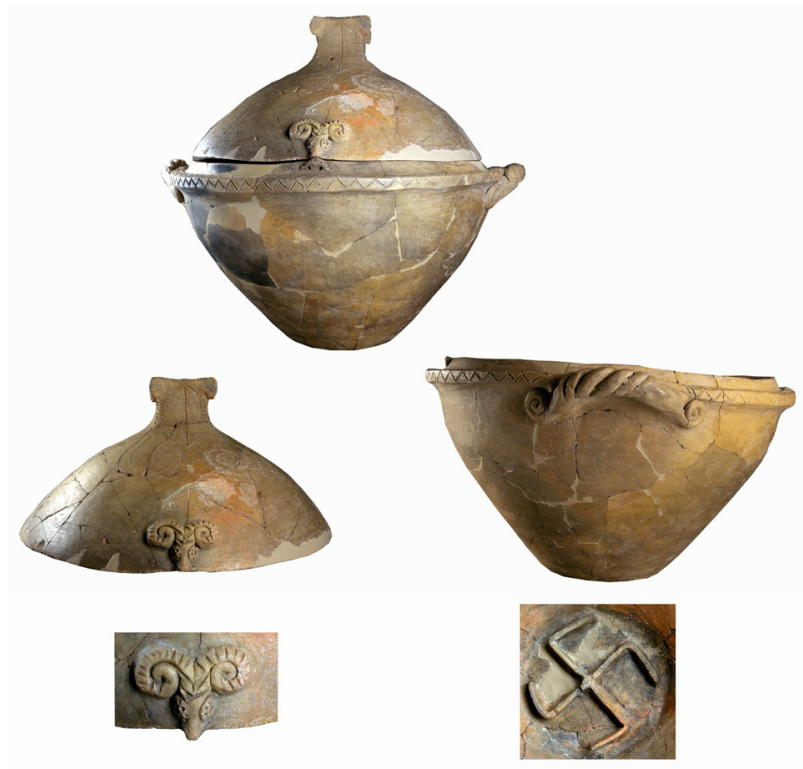

Figura 2. Diferentes vistas y detalles de la marmita (fotografías Maria Trigo Prunera)

\section{El contexto arqueológico}

El ámbito en el que se exhumó la marmita, el 8, está situado al SE del conjunto integrado por los ámbitos 6 y 7 y la torre semicircular (Torre 1) que constituían el agregado arquitectónico-funcional donde se ubicaba el taller de procesado del lino excavado con anterioridad, recuperado en un excelente estado de conservación y ya publicado (Rafel et al. 1994) (Fig. 3). De hecho, la decisión de excavar en esta zona fue planteada para comprobar si dicho conjunto productivo estaba ya completo o, por el contrario, constaba de más estancias situadas en este sector sudeste.

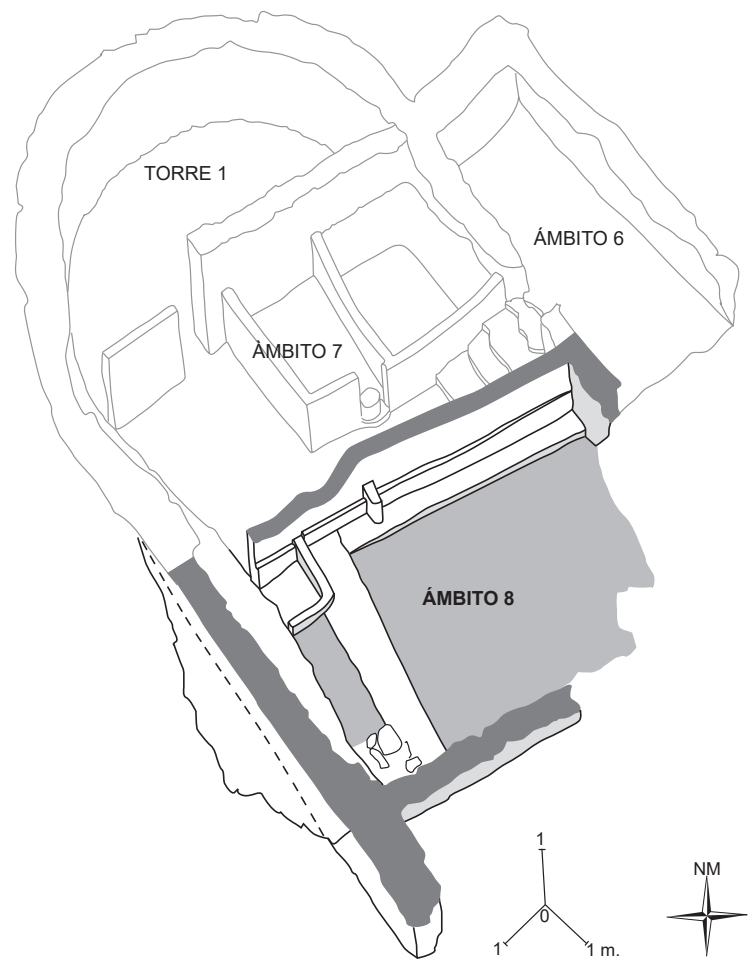

Figura 3. Perspectiva esquemática del Ámbito 8 y de su situación en relación al conjunto del taller textil a partir de los restos conservados 
La estancia 8 en cuestión linda con otro donde se documentaron los depósitos de tratamiento del lino (Ámbito 7), aunque se sitúa a un nivel inferior pues el área del asentamiento donde se emplazan estas construcciones se dispone siguiendo la pronunciada pendiente del cerro en sentido noroeste-sudeste. Un muro con base de piedra y alzado de adobes (U.E. 300) (Fig. 4), con sendos contrafuertes a lado y lado y con un enlucido de arcilla separa ambos ámbitos. Por el lado suroeste la estancia queda delimitada por la muralla que flanquea el asentamiento (U.E. 111), que en este punto presenta un desplome hacia el sudoeste. Por el sur y el nordeste la estructura está limitada por sendos muros de piedra (U.Es. 170 y 434). El ámbito, de planta rectangular $(6,40 \mathrm{X} 4,82$ metros en su interior) tiene una superficie útil de $30,84 \mathrm{~m}^{2}$. En la parte conservada no se conservan accesos a la habitación, por lo que éste debió estar en la parte deteriorada, al este o nordeste. En esta parte debió estar también el acceso al ámbito 6, cuya parte sureste tampoco se conservó. Dicho espacio 6 comunica con el 7 -donde se hallaban los depósitos de enriado de lino- que comunicaba con la Torre 1, pero que no tenía acceso directo al exterior. Una calle o espacio abierto debía dar acceso a ambos ámbitos, 6 y 8.

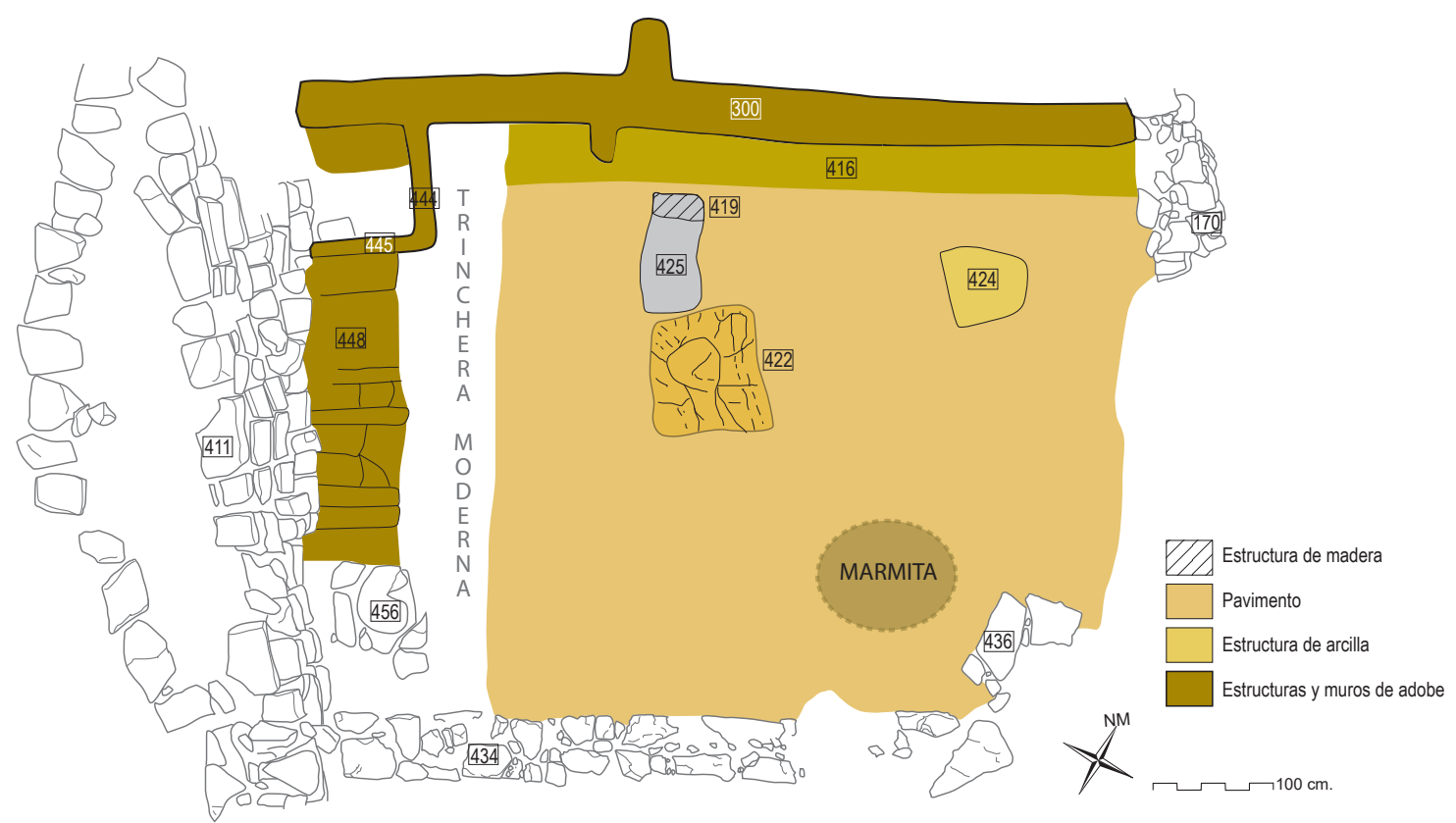

Figura 4. Planta del Ámbito 8 del Coll del Moro de Gandesa sobre el hogar del cual se exhumó la marmita decorada

Las excavaciones que se han llevado a cabo recientemente en el yacimiento (Jornet et al. 2016) han documentado al nordeste del ámbito 8 y adosado al ámbito 6 un complejo artesanal integrado por una torre semicircular (Torre 2) que comunica a través de dos puertas con un edificio de al menos $50 \mathrm{~m}^{2}$ cuya función era la de lagar. Uno de los dos compartimentos en que se halla dividida la torre funcionaba como almacén de tinajas, quizás para vino, el otro, de función más incierta, podría haber estado dedicado a actividades de teneduría que aprovecharían la rapa de la uva procesada en el lagar anexo y en al menos alguna de las estancias de los pisos superiores del conjunto se desarrollarían actividades textiles, a tenor del volumen significativo de pondera hallados en los estratos de derrumbe. Los nuevos datos, sumados a los antiguos, ponen de manifiesto de forma clara que nos hallamos ante un barrio artesanal, donde se documentan, por el momento, distintas actividades textiles, vinificación y quizás también adobería (Fig. 5). 


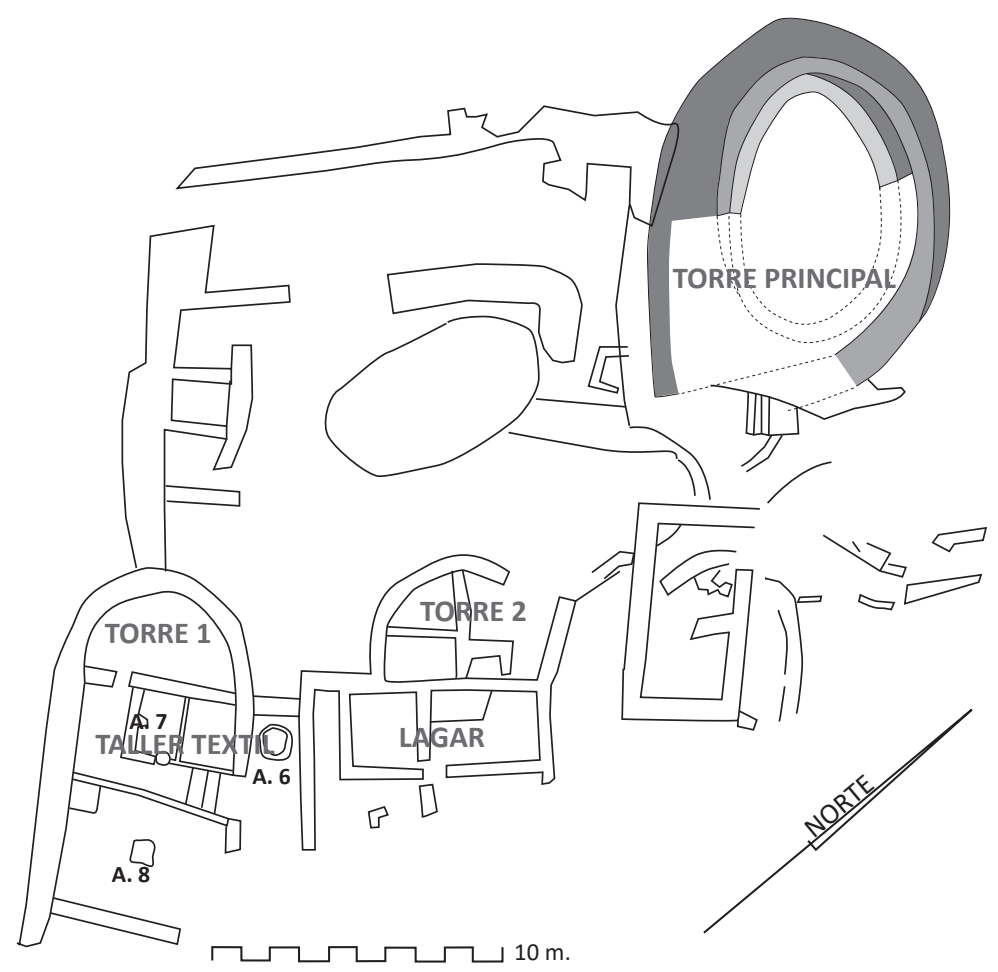

Figura 5. Planta general esquemática del Coll del Moro de Gandesa. Se pueden apreciar los conjuntos productivos dedicados al textil y a la vinificación y el ámbito 8 , donde apareció la marmita cultual

La conservación del ámbito 8 es desigual. El extremo nordeste y el ángulo sudeste están muy mal conservados, de tal forma que en el momento de la excavación faltaba buena parte del muro U.E. 170 y del muro U.E. 434. Lo que quedaba del primero de ellos (170), conservado a poco más de un metro de altura máxima, sugiere que era completamente de piedra, mientras que el pésimo estado de conservación del segundo (434) impide hacer conjeturas sobre este particular. El resto de la estancia presenta buen estado de conservación, si exceptuamos el desplome de la muralla (U.E. 111) hacia el exterior de la misma y la presencia de una trinchera moderna que cruza todo el ámbito en sentido noroeste-sudeste y que fue practicada para la construcción de un moderno muro de contención.

Un banco corrido de arcilla (U.E. 416), de $40 \mathrm{~cm}$. de anchura, se adosa al muro noroeste (U.E. 300). Otra banqueta de 66-68 cm. de anchura (U.E. 448), manufacturada con adobes puestos de través, que se adosa a la muralla (U.E. 111), queda interrumpida antes de llegar al ángulo sur de la habitación por una estructura de piedra de función indeterminada. El ángulo oeste de la habitación está ocupado por un depósito cuadrangular ( 80 X $90 \mathrm{~cm}$.) formado por los propios muros de la habitación y dos muretes de adobes (U.Es. 444 y 445). La solera del depósito estaba también revestida por adobes. La estancia tenía un pavimento de arcilla y en su parte central un hogar (U.E. 422), aunque algo descentrado respecto del ámbito. Consistía en una superficie rectangular, aunque tendente al cuadrado $(90 \times 100 \mathrm{~cm})$, con los ángulos redondeados, hecha de arcilla y muy ligeramente elevada sobre el pavimento. Presentaba la superficie muy lisa, endurecida y resquebrajada por la acción del fuego. Sobre ella se recuperó el vaso que presentamos. Cerca de lo que fue el ángulo este del ámbito se localizó un grupo de piedras (U.E. 436) con enlucido de arcilla, en mal estado de conservación, que podría haber correspondido a otro depósito de esquina, hecho en este caso de piedra. Al oeste de esta estructura se exhumó el vaso que presentamos (vide fig. 4). Estaba completo, en posición, aplastado y con algunos de sus fragmentos quemados, mientras que en otros no se observa tal circunstancia, por lo que parece que se quemó con posterioridad a su rotura. Próxima al ángulo norte se ubica otra estructura de arcilla (U.E. 424) que se eleva entre 2 y $3 \mathrm{~cm}$. sobre el pavimento y que presenta planta poligonal irregular $(c .62 X 62 \mathrm{~cm}$.), superficie 
horizontal y lisa y una rebaba que define su perímetro. Se trataba tal vez de una base para colocar algún elemento del ajuar de la estancia, quizás un gran vaso de almacén. Entre el hogar y la banqueta de arcilla hay una estructura en negativo (U.E. 425) de planta subrectangular $(65$ X $20 \mathrm{~cm}$.) que consistía en una leve impronta en el pavimento. Y, finalmente, al pie de la banqueta y unida a ella por su parte noroeste $-\mathrm{y}$, sin duda, en relación funcional- un agujero rectangular $(9-10$ X $20 \mathrm{~cm}$. y $24-28 \mathrm{~cm}$. de profundidad, U.E. 418) contenía un poste de madera cuadrangular carbonizado (U.E. 419). La madera es de encina (Quercus sp. caducifolio) y pertenecía en su origen a un porte arbóreo de gran calibre (tronco grande/mediano o rama grande). Para la elaboración del poste se utilizó el duramen, ${ }^{3}$ explotando, pues, el núcleo de la madera (Marguerie y Hunot 2007: 1419). Se registran galerías de insectos, alteración que (aunque no se constaten las condiciones en que éstos atacan la madera) podría indicar un uso destinado a la construcción o la elaboración de objetos (Martín Seijo 2013: 136; Carrión y Badal 2004). ${ }^{4}$ Plantear hipótesis sobre la estructura de cubierta es arriesgado, pues, si bien hay que mencionar que las medidas de la habitación parecen algo grandes para ser cubiertas con vigas sin sostén alguno, la base del poste recuperado (U.E. 419) no parece que se planteara como sostén de la cubierta pues está colocado en posición completamente excéntrica respecto a la habitación, distando $50 \mathrm{~cm}$. del muro U.E. 300. Este planteamiento, unido a las características anatómicas de la madera del poste, apunta más a algún elemento del mobiliario de la habitación. Es reseñable la considerable profundidad del agujero que alojó el poste en relación a su largo y ancho, con la que se manifiesta el deseo de estabilidad de la madera colocada en él.

La estratigrafía de la estancia estaba integrada por un paquete de niveles de derrumbe de la superestructura, con abundancia de adobes, argamasa de cal y piedra. Por debajo de éstos se localizó el nivel de uso que cubría todo el ámbito y se superponía al pavimento, de arcilla endurecida, y a los restos del mobiliario. De grosor variable, aunque en general de muy poca potencia, dicho nivel presentaba color negruzco y gran cantidad de carbones; sin embargo, no se observaron signos de rubefacción en los muros y elementos inmuebles de la estancia. El material mueble exhumado en el horizonte de uso consiste, además de la marmita que presentamos en este artículo, en un dolium o pithos ibérico prácticamente entero, varias tapaderas, un jarrito y piezas hechas a mano (tapaderas de arcilla sin cocer, soportes en creciente, también de arcilla sin cocer, para sostener la base de grandes vasos, vasitos y jarros); en definitiva, material claramente doméstico sin elementos diagnósticos precisos en relación a la cronología. En el paquete estratigráfico de derrumbe, sin embargo, se recuperaron diversos fragmentos sin forma de campaniense A, que no facilitan precisión cronológica, pero que permiten proponer una fecha de obliteración del conjunto en la segunda mitad del siglo III ane o, como muy tarde, los primeros años del II. Ello indicaría que la obliteración del ámbito 8 pudiera haberse producido coetáneamente a la del colindante taller de lino, cuyo momento final viene marcado por la presencia en los niveles inferiores de un bol (Lamb 27) del taller de las pequeñas estampillas y una enócoe de barniz rojo ilergete (forma Junyent 1.1), ambos fechables en el siglo III ane, y de campaniense A en los niveles superiores del horizonte de derrumbe. Por otra parte, las excavaciones llevadas a cabo recientemente (2014-105) en el conjunto formado por la Torre 2 y el lagar han proporcionado datos que indican su destrucción por un incendio en una fecha que, basándose en el barniz negro, los excavadores sitúan entre finales del siglo III e inicios del II ane (Jornet et al. 2016: 355).

\section{Acerca de la decoración de la pieza}

Dos elementos sobresalen claramente en el programa decorativo de la pieza: el carnero y la esvástica y a ellos vamos a referirnos pormenorizadamente. Más difícil es interpretar los motivos incisos ante coccionem en forma de doble flecha y de tallos o varillas rematadas por volutas. Lo más probable es que se trate de estilizaciones vegetales del tipo que contemporáneamente se documenta en las cerámicas pintadas ibéricas: quizás hojas cordiformes y algún tipo de roleo; sin embargo, para éstos últimos cabrían otras interpretaciones quizás relacionadas con los cuernos del carnero, a pesar de que se sitúan en posición de rotación contraria a éstos. Una de las tapaderas con asa zoomorfa representando carneros que se documentó en las excavaciones antiguas de Tivissa presenta una decoración plástica sobre el borde, en posición perpendicular a éste, que 
consiste en un elemento vertical rematado con dos volutas antitéticas que se interpretaron en su momento como dos serpientes afrontadas (Vilaseca et al. 1949: 31, Maderuelo y Pastor 1981: 169, figs. 6 y 172) o bien como un motivo floral (Pallarès 1984, en Asensio et al. 1996: 184) (Fig. 6). El hecho de que se trate de una representación esquemática y de estilo algo grosero dificulta la interpretación del motivo de esta pieza de Tivissa, si bien no está de más recordar la frecuente asociación carnero-serpiente en los ámbitos griego y celta y su vinculación al Más Allá, una asociación que en el caso peninsular tiene su paradigma en uno de los morillos de Reillo (Cuenca) que presenta un carnero con un baquetón decorado con triángulos incisos en la base del cuello y el cuerpo de la pieza decorado con una serie de serpientes paralelas. Cabe señalar que, además, se documentaron en este último yacimiento vasos plásticos con cabezas de carnero (Almagro-Gorbea y Lorrio 2011: 44, 80-85, 106-108, fig. 33).

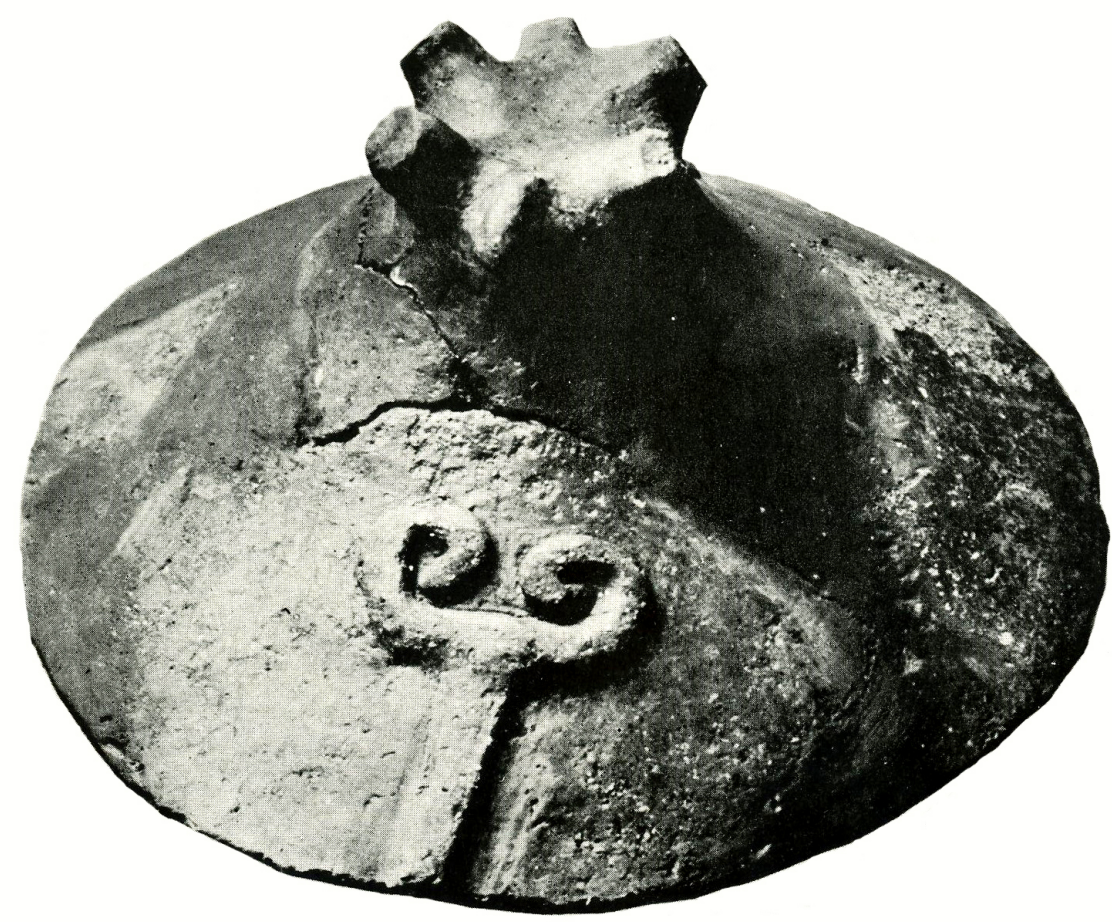

Figura 6. Tapadera de Tivissa (Vilaseca et al. 1949)

\subsection{El carnero}

El carnero constituye un motivo presente en la mayor parte de ambientes mediterráneos y europeos continentales -éstos últimos por lo general vinculados al ámbito cético-y aparece representado sobre diferentes tipos de materiales, soportes y elementos funcionales. Generalmente se asocia al hogar, tanto en sentido literal como simbólico, y al culto a los antepasados. Dos obras relativamente recientes (Moneo 2003, Almagro-Gorbea, Lorrio 2011: esp. 43-49 y fig. 18A) exploran en profundidad el simbolismo de este animal, lo que nos exime de reproducir en su integridad los abundantes datos sobre el tema. Señalaremos solamente que en la Península aparecen sobre exvotos, morillos y escultura; asimismo los ovicápridos se documentan en yacimientos peninsulares como víctimas sacrificiales propiciatorias en contextos de hábitat $\mathrm{y}$, en un número de casos significativo, asociados a enterramientos infantiles, también en contextos domésticos. Una pieza excepcional, el bronce llamado del Guerrero sacrificando un carnero de Puerta de Segura, que Almagro-Grobea y Lorrio fechan hacia 490 ane e interpretan como un rex ibérico, atestigua la importancia de este tipo de sacrificio en la Península Ibérica (Almagro-Gorbea y Lorrio 2011: 17-77). 


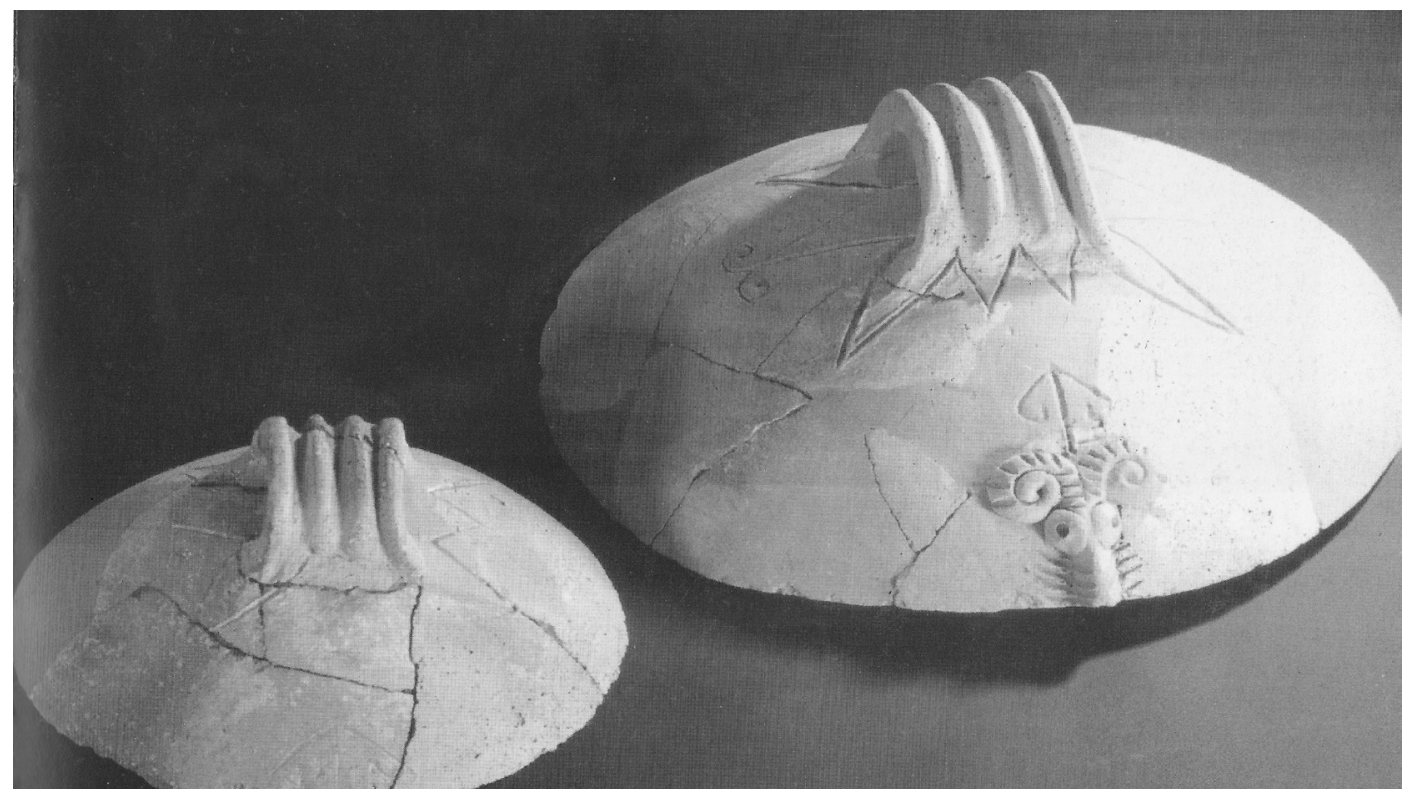

Figura 7. Tapaderas procedentes del Matarranya-Bajo Aragón, sin ubicación específica (Marín 2000)

En el nordeste de la Península Ibérica se documentan diversos ejemplares de morillos con representaciones de este animal (morillos prismáticos tipo $\mathrm{D}$ de Almagro-Gorbea y Lorrio 2011: 93-94) fechables, cuando menos, desde finales del siglo VI ane. El carnero constituye además uno de los animales más representados en los colgantes del ibérico antiguo con peana sogueada o acanalada que se documentan en Cataluña y el norte de la Comunidad Valenciana, especialmente en la franja costera, así como en Menorca (Rafel 1997).

Durante el ibérico pleno las representaciones de carnero proliferan en producciones vasculares con elementos decorativos en relieve, especialmente en el curso inferior del Ebro. Una tapadera recuperada en un yacimiento indeterminado y expoliado en el margen inferior derecho del Ebro, y desgraciadamente hoy desaparecida, es el paralelo más cercano con que contamos. Se trata de una tapadera de labio biselado con asa de pomo macizo cuadrífida rodeada de líneas incisas en zigzag que presenta decoración plástica de un carnero idéntico al nuestro tanto en la forma del trazo como en su situación en la pieza (Marín 2000) (Fig.7).

Tres tapaderas de este tipo, aunque sin carnero, se documentan en el vecino yacimiento de Sant Antoni de Calaceit) (Jornet 2017: 106, figs. 9.43, 9; 184 y 10.11, 2, 3) (Fig. 8), donde algunas decoraciones plásticas e incisas de piezas a mano parecen poder asimilarse a representaciones esquemáticas de carne- ro. En algunos casos mediante trazos incisos sobre la superficie de la pared (Cabré 1910: Lám. 72, fig. 94/95.6 y Lám. 76, fig. 100.1) y en otros casos ciertos detalles plásticos sobre el pomo macizo de tapaderas parecen indicarse los cuernos y el hocico, aunque sin motivos incisos (Jornet 2017: 184, fig. 10.11, $5)$, mientras que en otros la decoración plástica se aplica sobre el cuerpo de la tapadera (Jornet 2017: 184, fig. 10.11, 7) (Fig. 9) conformando un tipo decorativo que recuerda a alguno del Castellet de Banyoles en Tivissa Banyoles (Asensio et al. 1996: 186, fig. 17, 1). Finalmente, hay que recordar las tres tapaderas procedentes de este último yacimiento, de perfil cónico y con asa de pomo en forma de doble cabeza de carnero (Vilaseca et al. 1949: 28, láms. X y XI). Se trata de cerámicas a mano, como la del Coll del Moro, próximas geográficamente y también cronológicamente a nuestra pieza. Durante las excavaciones de los últimos años en el Castellet de Banyoles han aparecido otras tapaderas con asas con representaciones de carnero en un contexto material que parece apuntar a un conjunto ritual. ${ }^{5}$ Cabe recordar, por otra parte, que entre las conocidas piezas de vajilla metálica recuperadas en este yacimiento hay la fiala con ómfalo con cabeza de lobo y con una escena de sacrificio de un carnero por dos daimones alados que Almagro Gorbea (1990 y 1996) identifica como representación del culto al antepasado de un dinasta o régulo ibérico. 

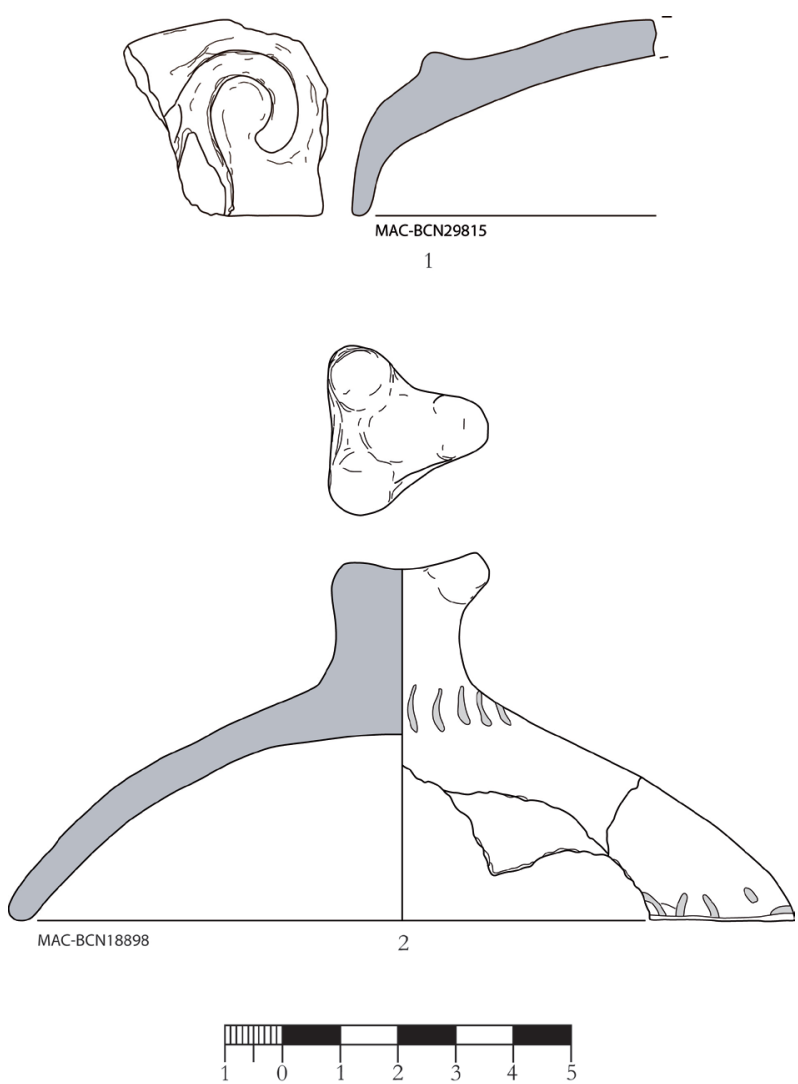

Figura 8. Tapaderas de San Antoni de Calaceit (1: Cabré 1910. 2: Jornet 2017).
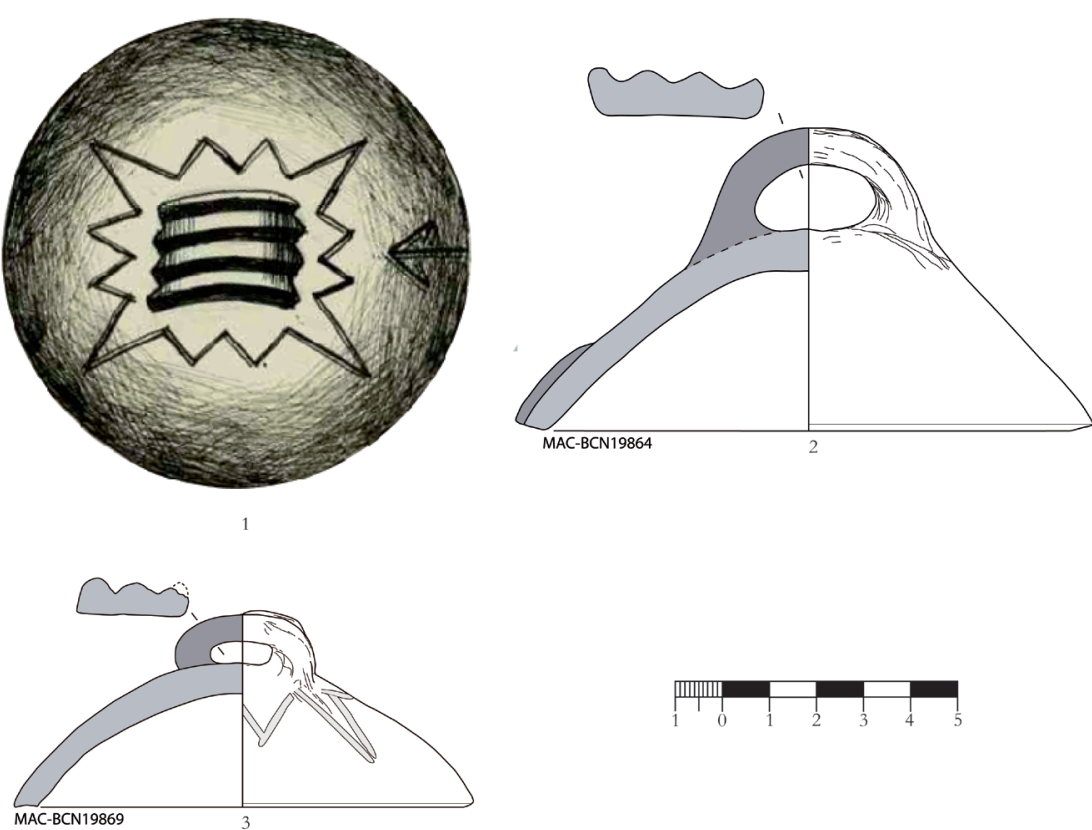

Figura 9. Tapaderas de San Antoni de Calaceit (Jornet 2017) 


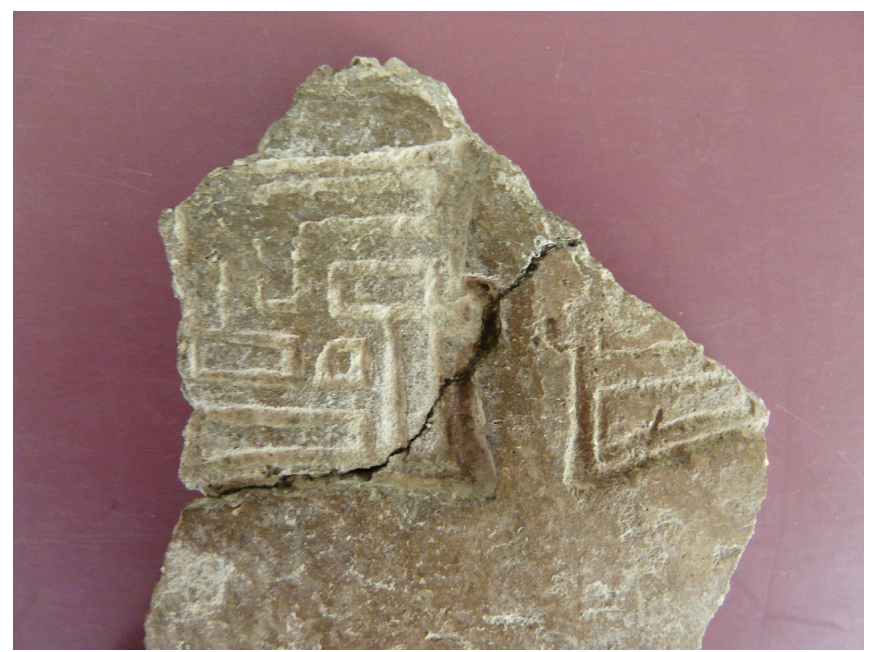

Figura 10. Fragmento cerámico con esvástica del Cerro de la Mesa (Toledo). Foto Juan Pereira

\subsection{La esvástica}

La esvástica es un símbolo que ha suscitado una gran atención tanto por parte de investigadores como de estudiosos de todo tipo (Wilson 1896), pues a su interés académico se une su carácter de emblema político en la reciente historia europea, al que no ha sido ajena su vinculación, muchas veces abusiva, al ámbito indoeuropeo y, especialmente en el caso de la Península Ibérica, celta (vide a título ilustrativo Arrinda 1992: 383-432; De Pablo 2009: 111112; Sopeña 1987; Benítez de Lugo; Moraleda 2013: 224; Baquedano 2013: 403 y 405).

En realidad el motivo de la esvástica se documenta en zonas geográficas muy diversas y con cronologías también muy distintas. Al menos desde el Neolítico se documenta en ambiente griego, donde no deja de utilizarse durante el Geométrico y el período griego clásico sobre soportes diversos, ya sean cerámicos, metálicos o en acuñaciones, como las monedas siracusanas de Timoleonte del siglo IV ane. $\mathrm{Su}$ presencia es, asimismo, frecuente en Italia desde el Villanoviano, donde aparece mayormente como decoración de urnas funerarias. El colgante de oro de Bolsena conservado en el Museo del Louvre atestigua la perduración del símbolo en época etrusca y se documenta también en el período romano. En el Languedoc se documenta, especialmente en los siglos IV-III, en los llamados hogares-altar decorados (Dedet et al. 1968; Roux y Raux 1966) y en general en el contexto gálico sobre piezas emblemáticas como la falera de la tumba de carro de Bourq (Champaña-Ardenas) (Lambot 2005) o el casco (s. IV ane) de la tumba, también de carro, de La Gorge-Meillet del Marne (Olivier y Brière 2016). Sin embargo, la enorme difusión del símbolo, tanto en sentido geográfico como cronológico, dificulta establecer su trazabilidad, aunque no queremos dejar de remarcar que, en lo relativo a la Península Ibérica, debe tenerse en consideración el peso del vector mediterráneo y más teniendo en cuenta la teoría de Marie-Yvane Daire que ha estudiado la iconográfica de la esvástica en la Galia, donde la cronología más antigua es el S. VI ane, igual que en la Península Ibérica, y ha llegado a la conclusión de que es un símbolo que llega a través de la influencia mediterránea (Daire, 2011, 41-52). Si bien es cierto que la mayor concentración de ítems decorados con esvástica se produce en al ámbito celtibérico, no es menos cierto que se trata de manifestaciones relativamente tardías, que poco tienen que ver con nuestro ejemplar.

Los testimonios encontrados de tetrasqueles rectilíneos anteriores al siglo III ane en la Península Ibérica han aparecido sobre diferentes soportes y con funciones distintas: un recipiente cerámico, un morillo, sellos, una falera y un broche de cinturón. Un ejemplar inédito del Cerro de la Mesa (Toledo) proporcionado por Juan Pereira muestra un fragmento de cuerpo de una cerámica hecha a mano del siglo IV ane con representaciones de una esvástica completa y otra parcial, una al lado de la otra, con dirección dextrógira. Fueron realizadas con un sello, lo cual se puede apreciar por el hundimiento en la arci- 
lla creado por la línea cuadrangular que limita el tetrasquel (Fig. 10). Uno de los dos morillos de los Molinicos de Moratalla en Murcia (Fig. 11) presenta decoración incisa en cada una de sus caras laterales con dos series de cinco esvásticas cada una en dirección dextrógira alternadas con otras cinco aspas (Lillo Carpio 1981: MOL. XIV). Desgraciadamente su cronología no se ha podido fijar con precisión, si bien debe situarse entre finales del siglo VI ane y mediados del s. IV. En el poblado de la Bastida de les Alcusses (Mogente, Valencia) se recuperó una estampilla o sello cuadrangular de 4,1 cm de anchura, manufacturado en terracota y con un tetrasquel en negativo, enmarcado por líneas rectas y cortas a cada lado (Fig. 12). Su dirección es dextrógira y la cronología corresponde al s. IV ane (Bonet y Vives-Ferrándiz, 2011: 248 y 250). Algunos de los ejemplos más significativos de las representaciones de esvástica aparecen decorando pequeñas placas cuadrangulares de bronce que se han venido identificando como "botones" debido a la presencia de una anilla en su parte trasera que se suponía para su sujeción. Sin embargo, la existencia del ejemplar en arcilla que aparece en el poblado de la Bastida y, sobre todo, la existencia de útiles con similar estructura en donde se sustituye la esvástica por un letrero, como el que se muestra en el museo de Sagunto, nos lleva a proponer que realmente nos encontramos ante sellos. Forman el conjunto con representaciones de esvásticas más importante dentro de la Península Ibérica en el Ibérico pleno. Tres ejemplares, datados todos ellos en el s. IV ane, presentan características similares: sellos realizados en bronce y con la cruz gamada cubriendo toda la superficie rectangular de los mismos en bajo relieve con dirección dextró- gira. Han aparecido en el yacimiento del Cerro de las Cabezas (Valdepeñas, Ciudad Real) en la Oretania septentrional (Benítez de Lugo y Moraleda Sierra 2013), en el poblado de La Bastida de les Alcusses (Bonet Rosado y Vives-Ferrándiz, 2011: 173 y 248; Silgo Gauche 2013: 201 y 222), y en la sepultura 177 de la necrópolis del Cabecico del Tesoro en Verdolay (en exposición en el Museo de Murcia). Por otra parte, tenemos otros dos sellos en bronce que, a pesar de ser distintos a los anteriores, tienen puntos en común que los engloban en esta categoría. Están formados por un tetrasquel levógiro recortado, delimitado por una línea cuadrangular y con una gran anilla detrás. Están fechados también en el s. IV ane. Uno de ellos fue hallado en la tumba 260 del Cabecico del Tesoro en Verdolay y el segundo en la sepultura 11/145 de la necrópolis ibérica de los Castellones de Ceal (Hinojares, Jaen) (Chapa Brunet et al. 1991: 337- 341). La falera apareció en la necrópolis de Palomar del Pintado (Toledo). Está decorada con una esvástica que presenta acanaladuras para incrustar algún tipo de material decorativo como hueso o marfil (Pereira Sieso et al., 2003: 156 y 158). $\mathrm{Su}$ cronología correspondería a la fase IV, que es el momento en que se hallaron los restos armamentísticos, lo que supone una cronología de la primera mitad del s. III ane. Por último, el broche de cinturón procede, según información proporcionada por Isabel Baquedano, de la tumba 545 de la necrópolis vetona de la Osera (Ávila), correspondiente a la zona III, nivel I, datado entre 425-350 ane. Es de bronce y presenta una esvástica con dirección levógira en el centro, rodeada por líneas con forma cuadrangular y pequeñas aspas circundándola (Cabré y Aguiló 1937: Lám XXII).

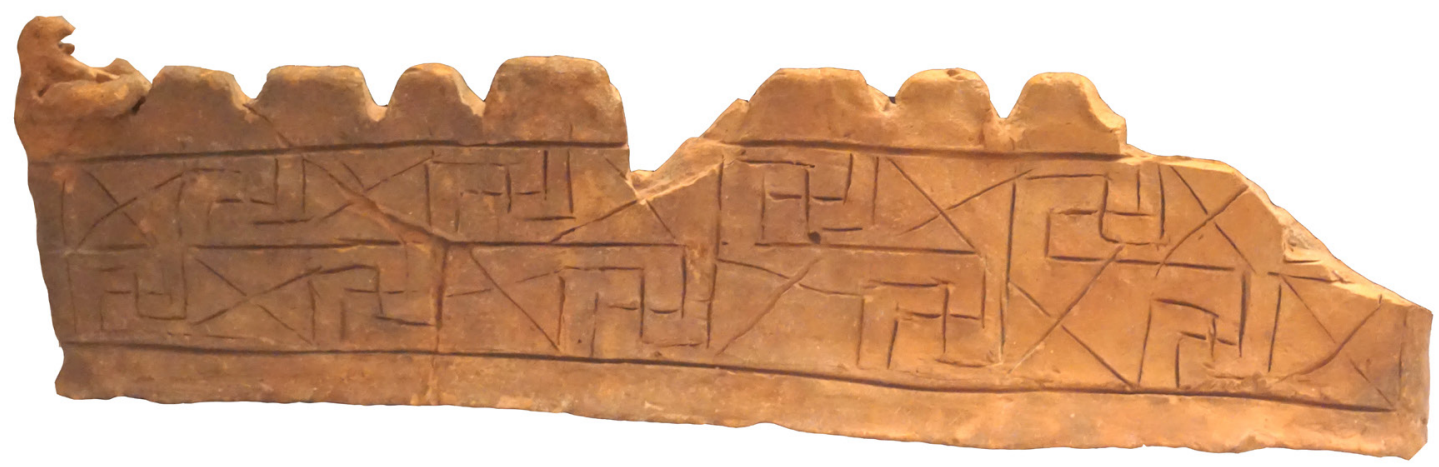

Figura 11. Morillo con decoración de esvástica procedente del Molinico de Moratalla (Murcia). Foto P. Burillo 
Así pues, la representación más antigua documentada hasta la fecha en la Península Ibérica corresponde al morillo de los Molinicos de Moratalla. Los restante hallazgos que hemos reseñado se sitúan en el siglo IV ane, a excepción de la falera del Palomar del Pintado, de la primera mitad del siglo siguiente.

La amplia representación de esvásticas en el mundo antiguo sugiere que su significado podría estar sujeto a variaciones en función de los diferentes contextos ideológico-culturales. Con carácter general, sin embargo, de las diversas interpretaciones propuestas (Díez de Velasco 1992: 176-177; Felolo 2010: 134-136; Godwin 2001: 174-176) quizás la más sólida, y también la más clásica, sea la que identifica la esvástica con el sol y su desplazamiento en el cielo (Déchelette 1909; López Pampló 1982: 77-107).

\section{Consideraciones finales: actividades domésticas y artesanales versus prácticas rituales}

La vasija que presentamos y algunos de sus elementos contextuales sugieren una función ritual y, por extensión, la práctica de ritos en la habitación 8 en la que fue recuperada. El vaso presenta un desarrollo iconográfico, cuyos elementos más parlantes son el carnero y la esvástica, que indican que, sin lugar a dudas, se trataba de una pieza ceremonial.

Hemos hecho ya referencia a la profunda simbología del carnero en el contexto peninsular, donde se vincula frecuentemente al hogar. Nuestra vasija fue hallada precisamente en un hogar cuadrangular, de factura constructiva relativamente simple, hecho que no quita significación a la asociación. En todas las culturas antiguas el hogar doméstico alberga un simbolismo vinculado a la familia y, posiblemente, a cultos relacionados con los antepasados de su linaje (Moneo 2003: 71-72; Almagro-Gorbea y Lorrio 2011: 63-64). Queremos resaltar aquí que los materiales aparecidos en la estancia 8 del Coll del Moro estaban todos fragmentados y revueltos y, además, no eran muy abundantes. Solo dos piezas presentaban un alto grado de integridad, el pithos y la vasija que presentamos que, de algún modo, parecen haber sido obliterados completos adrede. Sin embargo, el resto del equipamiento mueble recuperado en el ámbito es compatible con una función meramente doméstica.
Se mencionan a menudo como ejemplo de hogares rituales los que con gran frecuencia se documentan en el Languedoc, muchas veces decorados; sin embargo, una revisión reciente cuestiona su interpretación tradicional como altares (Dedet et al. 1968), en función de los datos contextuales documentados en Lattes. En dicho yacimiento se ha realizado un estudio pormenorizado de los abundantes (236) hogares documentados durante la Segunda Edad del Hierro (Roux y Raux 1996). De ellos, 86 ejemplares eran cuadrangulares, de los cuales 22 decorados. Los hogares cuadrangulares de Lattes se encuentran siempre en la pieza principal de la casa. El examen de los hallazgos muebles a ellos asociados (cenizas, restos de fauna, restos de vajilla), así como las señales de un uso continuado, lleva a los autores del estudio a defender para los mismos una función de iluminación, reunión y cocción de alimentos, si bien van a veces acompañados en la misma casa de hogares de otras tipologías, que tenían un uso más propiamente culinario. En definitiva los autores concluyen que "une vocation cultuelle, sans être exclue, ne peut donc plus être considérée comme unique fonction de ce type de foyer" (Roux y Raux 1996: 409). Por cuanto respecta al resto de elementos inmuebles de la estancia del Coll del Moro, banquetas y depósitos-contenedores, se hace difícil llegar a conclusión alguna, pues, aunque no faltan elementos de este tipo en lugares de culto, no son, ni mucho menos, privativos de los mismos. El tipo de distribución interna (hogar construido, banquetas perimetrales, depósito, posible betilo, suelo preparado y endurecido) no resulta rara en ámbitos del siglo III ane de la zona. Así lo podemos comprobar en distintos ámbitos del Castellet de Banyoles de Tivissa, más concretamente el 10 (Sanmartí et al. 2012), el recinto 183 del edificio 31 (Asensio et al. 2016), ambos interpretados como lugares de culto ante espacios abiertos o plazas públicas.

En cuanto a la esvástica, su dirección dextrógira es la común en el ámbito ibérico, si bien la situación dentro de la vasija y el modo en que ha sido realizada la hacen excepcional. Ha sido elaborada cuidadosamente al igual que las asas y la cabeza de carnero, pero es muy diferente a estas últimas que están a la vista del individuo que interactúa con la vasija, mientras que el tetrasquel está realizado para permanecer oculto. De hecho, la esvástica está creada para entrar en contacto directo con el producto, probable- 
mente líquido o semisólido, que se metiera en el recipiente, quedando de esta forma sumergido $\mathrm{y}$, si el líquido no era transparente, totalmente oculto. Ya que no iba a ser nunca visible al estar en el fondo interno der la pieza podría haberse realizado con unas simples incisiones, como el resto de representaciones halladas en la tapadera, pero se hizo en relieve y con una cuidada factura. Todo ello indica, unido a sus dimensiones, un especial tratamiento de este motivo y, con ello, una gran relevancia. Una representación de carácter solar que estaría en contacto directo con lo que contuviera dentro y que quizás transformaría ese producto en algo diferente, aportándole propiedades de tipo sobrenatural o mágico. Es difícil comprender su significación y solo se puede especular en ese sentido, pero lo que sí podemos decir con total seguridad es que estamos ante una cerámica de carácter ritual, que quizás dotaría de propiedades mágicas a la materia que entrara en contacto con ella.

En términos generales, el tipo de prácticas ideológico-rituales en uso en la Protohistoria Peninsular provocan como resultado que no siempre sea fácil diferenciar los espacios específicamente dedicados al culto de aquellos cuya función es otra, pero en los que se llevan a cabo actividades rituales. Aunque se han documentado santuarios en ámbitos habitacionales, lo más frecuente es documentar contextos donde la ritualidad está fuertemente imbricada con las actividades cotidianas de las comunidades. Ello es especialmente sensible en el marco geográfico y cultural en el cual nos movemos en este artículo, el nordeste peninsular, donde, a pesar de que se han interpretado tentativamente algunos espacios específicamente o primordialmente dedicados a actividades de culto, predominan acciones de carácter ritual en contextos cotidianos (Belarte y Sanmartí 1997).

En el área cultural y geográfica próxima al Coll del Moro de Gandesa Lucas (1989) propuso interpretar como un espacio de culto la habitación 1 del Tossal Redó de Calaceite donde apareció el vaso teromorfo, al cual, como es bien conocido, acompañaban una serie de elementos interpretables como litúrgicos. Posteriormente, dicho espacio, junto con la habitación 2 de San Cristóbal de Mazaleón, han sido considerados "ámbitos diferenciales" (concepto que señala la dificultad de interpretación de este tipo de recintos) donde se practicaban ritos de comensalidad (Sardà et al. 2010). Con motivo de una revisión reciente del poblado de San Antonio de Calaceite (Jornet 2017: 277-80) se ha propuesto la interpretación de algunos de sus espacios como santuarios urbanos (sobre uno de los cuales ya llamó la atención Moneo 1995: 338), tomando como criterio diagnóstico principal, pero no único, la presencia de inhumaciones infantiles, sacrificios de animales, altares, un posible betilo, entre otros elementos de carácter mueble. El autor concluye proponiendo una serie de espacios de culto en cada uno de los barrios del poblado y en relación a los bloques definidos por la red viaria. Desgraciadamente, los datos con que se cuenta sobre las excavaciones en este yacimiento no permiten considerar esta hipótesis como firme, sino que deberá ser contrastada en futuras investigaciones en otros yacimientos paralelizables.

Hemos ya aludido en la descripción del contexto a la base del poste tallado en forma cua-

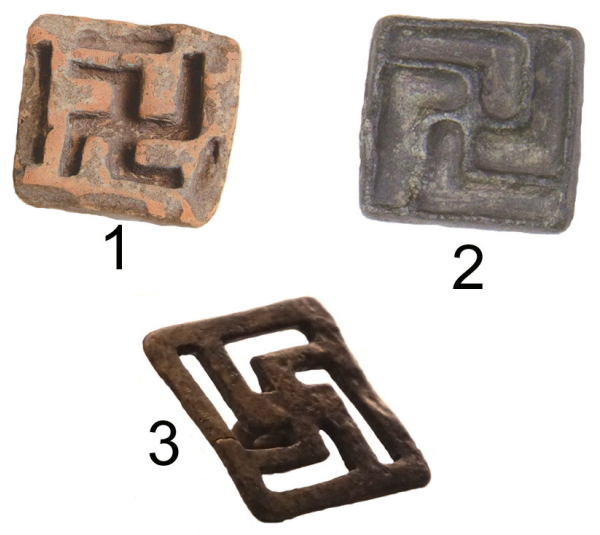

Figura 12. Sellos de La Bastida de les Alcusses (1 y 2) y de la tumba 260 del Cabecico del Tesoro de Verdolay (3). Fotos: Bonet Rosado y Vives-Ferrándiz Sánchez 2011 y Pilar Burillo-Cuadrado. 
drangular de madera del ámbito 8 del Coll del Moro y a la dificultad de interpretarlo en clave de elemento portante. Sugerimos -a título de hipótesis, pues los datos no permiten ir mucho más allá- que pudiera tratarse de un elemento de tipo betílico o bien de soporte de una ara, posiblemente más frecuentes en contextos ibéricos de lo documentado hasta la fecha, dada la tendencia anicónica de la religión ibérica (Martín Ceballos 2000-2001: 11-12). A ello cabría objetar que los betilos suelen estar indisolublemente vinculados a un material, la piedra. No obstante, la presencia en las estancias mencionadas de Tossal Redó y de San Cristóbal de elementos estructurales de barro decorados con motivos geométricos que podrían haber recubierto un elemento betílico (Lucas 1989: 198; Sardà et al. 2010: 5) o bien constituir bases de altar podrían dar algún apoyo a esta propuesta. Hay que hacer notar, por otra parte, que el poste en cuestión pudo estar decorado o esculpido, extremo éste que el estado del hallazgo impide precisar. En los edificios A y BF de Alorda Park (Calafell), la habitación 52 de Moleta del Remei (Alcanar) y en una de las estancias de Can Balençó (Argentona) se documentaron una especie de poyos circulares de piedra, de poca altura, con revestimiento enlucido que han sido también puestos en relación con actividades de culto, si bien solo en el caso del edificio A de Alorda este extremo parece razonablemente seguro (Belarte y Sanmartí 1997: 20-21). Por otra parte, un poste de madera sin trabajar localizado en posición no estructural en el mencionado edificio A de Alorda ha sido interpretado, de forma algo audaz, como el palo al que se ataba las víctimas sacrificiales (Id: 19). Elementos de este tipo han sido documentados en contextos alejados del nuestro, como por ejemplo el santuario chipriota de Amathonte (Columeau 2000: 159) donde entorno a un altar se documentan postes para atar los animales que se sacrificaban. Elementos de poste asociados a espacios donde se realizan cultos se documentan también en el Alto Chacón (Teruel) en un espacio con hogar y bancos corridos interrumpidos por dos postes contiguos que se interpretan como soportes de un ara sacrificial (Cabrera 2010: 134-135). Otro aspecto difícil de interpretar es la leve oquedad asociada al agujero de dicho poste de madera, cuya función se nos escapa completamente, a menos que, siguiendo la hipótesis que acabamos de mencionar de Belarte y Sanmartí pueda tener relación con la recogida de sangre del animal sacrificado. Todo ello mera especulación, pues no contamos con datos suficientes para que ésta se convierta en sólida hipótesis.

Es incontestable, sin embargo, el carácter ceremonial de la marmita decorada recuperada in situ, por lo que podemos afirmar que en el espacio 8 del poblado del Coll del Moro se desarrollaron sin duda rituales relacionados con el culto al hogar y, probablemente, a los antepasados. Más arriesgado resulta proponer la realización de sacrificios, aunque no es ni mucho menos descartable. A la vista de los datos es difícil concluir que se trate de un espacio dedicado exclusivamente al culto, pues cabe también la posibilidad de que en él se imbricaran actividades domésticas y ceremoniales. Sea como sea, el hallazgo aporta nuevas perspectivas sobre las actividades de culto y el mobiliario ceremonial en el nordeste peninsular, tan avaro respecto a este tipo de información.

\section{Notas}

* Las excavaciones en el ámbito 8 del Coll del Moro, que dieron lugar al hallazgo de la pieza que aquí se presenta, fueron realizadas gracias a una subvención del Servei d'Arqueologia i Paleontologia del Departament de Cultura de la Generalitat de Catalunya.

1. Fue la décima campaña de excavaciones en el yacimiento. Se centró en los ámbitos 1, 2, 3 y 8 . Fue codirigida por Núria Rafel y Mónica Blasco.

2. La restauración se efectuó en el Laboratori d'Arqueologia de la Universitat de Lleida y estuvo a cargo de Maria Trigo Prunera y Carme Prats Darder (Prats 2013: 481).

3. La estructura interna dura, pesada y resistente responsable de la sustentación.

4. Debemos los datos referidos a la madera del poste al examen que amablemente ha realizado de los restos del mismo Sílvia Vila.

5. Debemos la información sobre estos materiales en curso de estudio a la amabilidad de Jaume Noguera. 


\section{Bibliografía}

Almagro-Gorbea, M. (1990): L'Hellénisme dans la Culture Ibérique. XIII Congress für Klassische Archäeologie, Berlin 1988. Berlín: 113-127.

- (1996): Ideología y poder en Tartessos y el mundo ibérico. Discurso de ingreso en la Real Academia de la Historia, Madrid.

—., Lorrio, A.J. (2011): Teutates. El héroe fundador. Real Academia de la Historia, Bibliotheca Archaeologica Hispana núm. 36, Madrid.

Arrinda Albisu, A. (1992): Los vascos: de la magia al animismo. Instituto Labayru, Bilbao.

Asensio, D., Cela, X. y Ferrer, C. (1996): Els materials ceràmics del poblat ibèric del Castellet de Banyoles (Tivissa). Col·lecció Salvador Vilaseca de Reus. Pyrenae 2: 163-191.

—, Jornet, R., Miró, M.T, Sanmartí-Grego, J. (2016): L'excavació de la zona 3 en el Castellet de Banyoles (Tivissa, Ribera d'Ebre), un nou fragment de trama urbana en l'angle sud-oest de la ciutat ibèrica. Actes de les Primeres Jornades d'Arqueologia de les Terres de l'Ebre, Volum 1, Tortosa: 332-344.

Baquedano Beltrán, I. (2013): La necrópolis vettona de La Osera (Ávila, España): sistematización del conjunto. Universidad Complutense de Madrid.

Belarte, M.C., Sanmartí, E. (1997): Espais de culte i practiques rituals a la Catalunya protohistórica. Quaderns de Prehistòria i Arqueologia de Castelló 18: 7-32.

Benítez de Lugo Enrich, L., Moraleda Sierra, J.(2013): Símbolos, espacios y elementos ibéricos para el culto en Oretania Septentrional. Estado de la cuestión arqueológica, revisión crítica y nuevas aportaciones. Santuarios iberos: Territorio, ritualidad y memoria, Actas del Congreso El Santuario de la Cueva de La Lobera de Castellar. 1912-2012, Asociación para el desarrollo rural de la Comarca de El Condado: 213-270.

Bonet Rosado, H., Vives-Ferrándiz Sánchez, J., eds. (2011): La Bastida de les Alcusses. Museu de Prehistòria de València-Diputació de València.

Cabré y Aguiló, J. (1910): Catálogo Artístico-Monumental de la provincia de Teruel, Simurg. Fondos Digitalizados del CSIC. Cabré y Aguiló, J. 1937: Broches de cinturón de bronce damasquinados con oro y plata. Archivo Español de Arte y Arqueología 38, Madrid: 93-126.

Cabrera, A. (2010). El ritual del sacrificio de animales en la cultura ibèrica: una perspectiva arqueològica. Tesis Doctoral, Universidad Complutense de Madrid. [URL: http://eprints.ucm.es/11714/1/T32477. pdf].

Carrión, Y.; Badal, E. (2004): La presencia de hongos e insectos xilófagos en el carbón arqueológico. Propuestas de interpretación. Actas del V Congreso Ibérico de Arqueometría. Cádiz, 2003: 98-106.

Chapa Brunet, T., Pereira Sieso, J., Madrigal Relinchón, A., López Trapero, Mª T. (1991): La Sepultura 11/145 de la necrópolis ibérica de los Castellones de Ceal (Hinojares, Jaen). Trabajos de Prehistoria 48: $333-348$.

Columeau, P. (2000). Sacrifice et viande dans les sanctuaires grecs et chypriotes (VII s./I s. av. J.-C.) et l'apport de l'habitat de Kassopè. Pallas. Revue d'études antiques 52 (Paysage et alimentation dans le monde grec. Les innovations du premier millénaire av. J.C): 147-166.

Dairem M.Y. (2011): Le thème du quadriscèle: un aspect de l'iconographie du second Âge du Fer dans 1'Ouest de la France. Revue d'Études Celtiques XXXVII: 41-52.

Dedet, B., Duday, H., Fiches, J.L., Richard, J.C.M. (1968): Les “autels-foyer" en Languedoc. Omaggio a Fernand Benoit (RSL) II: 35-56.

De Pablo, S. (2009): El lauburu. Política, cultura e identidad nacional en torno a un símbolo del País Vasco. Memoria y Civilización 12, Universidad de Navarra: 109 - 153.

Déchelette, J.( 1909): Le culte du soleil aux temps préhistoriques. R. Arch. XIV, París: 306-357.

Díez de Velasco, F. (1992): Anotaciones a la iconografía y el simbolismo del laberinto en el mundo griego: el espacio de la iniciación. R. Olmos, coord., Coloquio sobre Teso y la Copa de Aison, Anejos de Archivo español de arqueología XII, Centro de Estudios Históricos CSIC: 175-200.

Felolo L. (2010): Una rosa dei venti neanderthaliana di 80 mila anni fa e le due Orse. $12^{\circ}$ Seminario di Archeoastronomia, Osservatorio Astronomico di Genova 17-18 aprile 2010, Associazione Ligure per lo Sviluppo degli Studi Archeoastronomici: 132-138.

Godwin, J. (2001): Il mito polare. L'archetipo dei Poli nella scienza, nel simbolismo e nell'occultismo. Roma, Edizioni Mediterranee: 174-179. 
Jornet Niella, R. (2017): El jaciment de Sant Antoni de Calaceit i el poblament ibèric de les comarques del Matarranya i la Terra Alta. Monografies del Museu d'Arqueologia de Catalunya-Barcelona, núm. 15. MAC. Barcelona.

Jornet, R., Belarte, C., Sanmartí-Grego, J., Asensio, D., Morer, J. (2016): Noves excavacions al nucli fortificat del Coll del Moro de Gandesa (2014-2015). En Actes de les Primeres Jornades d'Arqueologia de les Terres de l'Ebre, Volum 1, Tortosa: 345-358.

Lambot, B. (2005) : Les tombes à char et à harnachement de cavalier de Bourcq (Ardennes) et de Prunay (Marne). Journée Archéologique de Champagne-Ardenne, Direction régional des affaires Culturelles de Champagne-Ardenne, Châlons-en-Champagne : 18-24.

Lillo Carpio, P. A. (1981): El poblamiento ibérico en Murcia. Universidad de Murcia.

López Pampló, F. (1982): Mito sin mito "La Swastika". Ethnica 18, Barcelona: 75-108.

Lucas, R. (1989): El vaso teromorfo del poblado grande del Tossal Redó (Calaceite, Teruel) y su contexto arqueológico. CuPAUAM 16: 169-210.

Maderuelo, M.; Pastor, M. (1981): Excavaciones en Reillo (Cuenca). Noticiario Arqueológico Hispano 12, Madrid.

Marguerie, D.; Hunot, J.Y. (2007): Charcoal analysis and dendrology: dta from archaeological sites in north-western France. Journal of Archaeological Science 34 (9): 1417-1433.

Marín, A. (2000): El antes y el después de los íberos. 5000 años de población continuada en la Catalunya de poniente y el Maestrazgo aragonés. Horta de Sant Joan.

Martín Ceballos, M.C. (2000-2001): La representación de los dioses en el mundo ibérico. Lucentum XIX$\mathrm{XX}$.

Martín Seijo, M. (2013): A xestión do bosque e do monte dende a Idade do Ferro a época romana no noroeste da península Ibérica: Consumo de combustibles e producción de manufactures en madeira. Universidade de Santiago de Compostela. Santiago de Compostela. Tesis doctoral. [URL: https://minerva. usc.es/xmlui/handle/10347/7516].

Moneo, T. (2003): Religio Iberica. Santuarios, ritos y divinidades (siglos VII-I a.C.). Real Academia de la Historia, Bibliotheca Archaeologica Hispana núm. 20, Madrid.

Olivier, L., Brère, J. (2016): Autopsie d'une tombe gauloise. La tombe à char de la Gorge-Meillet à Somme-Tourbe (Marne). Cahiers du Musée d'Archéologie nationale 2.

Pallarès, R. (1984): El poblamiento ibérico de las comarcas de Tarragona (El Castellet de Banyoles, Tivissa, Ribera d'Ebre). Tesis doctoral inédita. Facultad de Geografía e Historia de la Universidad de Barcelona.

Pereira Sieso J., Ruiz Taboada, A. y Carrobles Santos J. (2003): Aportaciones del C-14 al mundo funerario carptetano: La necrópolis de Palomar de Pintado. Trabajos de Prehistoria 60, 2: 153-168.

Prats, C. (2013): Memòria de l'activitat portada a terme pel SCT-Laboratori d'Arqueologia de la Universitat de Lleida durant l'any 2012. Revista d'Arqueologia de Ponent 23: 479-481.

Rafel, N. (1997): Colgantes de bronce paleoibéricos en el N.E. de la península ibérica. Algunas reflexiones sobre las relaciones mediterráneas. Pyrenae 28: 99-117.

—, Blasco, M., Sales, J. (1994): Un taller ibérico de tratamiento de lino en el Coll del Moro de Gandesa (Tarragona). Trabajos de Prehistoria. 51, 2: 121-136.

Roux, J.C., Raux, S. (1996): Les foyers domestiques dans l'habitat lattois du IIe-Ier s. a.v.n.è.. Lattara 9: 401-432.

Sanmartí, J., Álvarez, R., Asensio, D., Jornet, R., Miró, M. (2012): Castellet de Banyoles (Tivissa): Una ciudad ibérica en el curso inferior del río Ebro. Archivo Español de Arqueología 85: 43-63.

Sardà, S., Fatás, L. Graells, R. (2010): Prácticas rituales, comensalidad e ideología en un espacio de transición. Ámbitos diferenciales en la Terra Alta-Matarraña (s. VII-VI a.C.). F. Burillo (coord.): Ritos y Mitos. VI Simposio sobre Celtíberos: 45-56.

Silgo Gauche, L. (2013): Recuerdos de Don Domingo Fletcher Valls (I). ARSE 47, Centro Arqueológico Saguntino: 179-210.

Sopeña, G. (1987): Dioses, ética y ritos. Prensas Universitarias, Zaragoza.

Vilaseca, S., Serra Ràfols, J. de C., Brull, L. (1949): Excavaciones del Plan Nacional en el Castellet de Bañolas de Tivisa (Tarragona). Informes y Memorias 20. Comisaría General de Excavaciones Arqueológicas. Madrid.

Wilson, Th. (1896): The Swastica: the Earliest Known Symbol, and Its Migrations; With Observations on the Migration of Certain Industries in Prehistoric Times, Smithsonian Institution, Washington D.C 